\title{
Cervical disc arthroplasty at C2-3: illustrative case
}

\author{
Jason $\mathrm{Ku}, \mathrm{BS},{ }^{1}$ Johnson $\mathrm{Ku}, \mathrm{BS},{ }^{1}$ Hsuan-Kan Chang, $\mathrm{MD},{ }^{2-4}$ and Jau-Ching $\mathrm{Wu}, \mathrm{MD}, \mathrm{PhD}^{2,3,5}$ \\ ${ }^{1}$ Department of Life Sciences, University of California, Los Angeles, California; '2Department of Neurosurgery, Neurological Institute, Taipei Veterans General Hospital, Taipei, Taiwan; \\ ${ }^{3}$ College of Medicine, ${ }^{4}$ Department of Biomedical Imaging and Radiological Sciences, and ${ }^{5}$ Institute of Pharmacology, National Yang Ming Chiao Tung University, Taipei, Taiwan
}

\begin{abstract}
BACKGROUND Since the beginning of the 21st century, cervical disc arthroplasty (CDA) has been accepted as an alternative to anterior cervical discectomy and fusion for surgical management of disc problems. The published clinical trials of CDA have included patients with radiculopathy or myelopathy caused by one- or two-level disc herniation at C3-7. However, it remains uncertain whether CDA is a viable option for C2-3 disc herniation.

OBSERVATIONS In this report, a 52-year-old man presented with hand numbness, arm pain, and myelopathic symptoms that were refractory to medical treatment for more than 6 months. The magnetic resonance images demonstrated herniated discs at C2-3, C3-4, and C4-5, causing stenosis. There was no ossification of posterior longitudinal ligament and the spine was mobile, so he received anterior discectomies with artificial disc replacement at each of the C2-3, C3-4, and C4-5 levels. The surgery went smoothly, and his neurological symptoms were promptly relieved. The postoperative radiographs at 24 months demonstrated a preserved range of motion at each level.
\end{abstract}

LESSONS To date, this was the first report of CDA performed at C2-3, which also involved three consecutive levels of disc replacement. The report suggested that both $\mathrm{C} 2-3$ and three-consecutive-level CDA may be a viable option for cervical disc disease.

https://thejns.org/doi/abs/10.3171/CASE21320

KEYWORDS ACDF; anterior cervical discectomy and fusion; CDA; cervical disc arthroplasty; artificial disc replacement; disc herniation; C2-3; three consecutive level

Since its first documentation in 1958, anterior cervical discectomy and fusion (ACDF) has been widely accepted as an effective and safe surgical option for single- or multilevel cervical disc herniation, causing cervical spondylotic myelopathy, radiculopathy, or both. ${ }^{1,2}$ To date, in neurosurgical practice, ACDF has been one of the most popular procedures that usually comes with high satisfaction and low complications in the subaxial cervical spine. ${ }^{3}$ Thus, ACDF is often regarded as the gold standard anterior surgical approach for cervical disc diseases. ${ }^{4}$ In contrast to the frequently encountered subaxial cervical spinal segments, disc herniation at C2-3 is far less common and usually related to trauma or associated with a hangman's fracture. Surgical options for C2-3 disc herniation include ACDF, posterior decompression, and procedure with or without instrumentation. ${ }^{5}$ Although infrequently seen, C2-3 ACDF reportedly also demonstrates good clinical outcomes and has often been suggested for unstable hangman fractures, ${ }^{6-8}$ despite the potential difficulty of the surgical approach.

The technology of cervical disc arthroplasty (CDA) has gained increasing popularity worldwide in the past decade. Many spine surgeons regard CDA as an alternative to ACDF for subaxial cervical spinal segments when preservation of the segmental mobility is optional. Common contraindications for CDA include kyphosis, ossification of posterior longitudinal ligament (OPLL), ankylosing segments, osteoporosis, and severe facet arthropathy that requires posterior decompression or fusion. ${ }^{9-14}$ The published clinical trials of the U.S. Food and Drug Administration investigational device exemption (FDA IDE) in the last decade have clearly supported the clinical success of CDA in the subaxial (C3-7) cervical spine. In data up to 8 or 10 years after surgery, CDA is as effective, viable, and durable as ACDF for one- and two-level cervical disc herniation

ABBREVIATIONS ACDF = anterior cervical discectomy and fusion; $C D A=$ cervical disc arthroplasty; OPLL = ossification of posterior longitudinal ligament; $\mathrm{ROM}=$ range of motion.

INCLUDE WHEN CITING Published August 2, 2021; DOI: 10.3171/CASE21320.

SUBMITTED May 23, 2021. ACCEPTED June 9, 2021.

(c) 2021 The authors, CC BY-NC-ND 4.0 (http://creativecommons.org/licenses/by-nc-nd/4.0/). 
or spondylosis that has caused radiculopathy or myelopathy. ${ }^{15-25}$ However, none of the FDA trials or above-mentioned case series have included patients with a $\mathrm{C} 2-3$ disc replacement. All the published clinical studies only focused on C3-7, either disc herniation or spondylosis, radiculopathy, or myelopathy, except for one case report of CDA at the upper thoracic spine $(T 1-2) .{ }^{26}$ Literature has suggested segmental mobility at the high cervical spine in normal subjects, ${ }^{27}$ and the range of motion (ROM) at C2-3 reportedly averaged $6.1^{\circ}$, as compared to that of $9.7^{\circ}$ at C5-6, which is considered the most mobile segment in the cervical spine. ${ }^{27}$

To date, it is unknown whether CDA at $\mathrm{C} 2-3$, such a high cervical segment, is a viable and effective surgical option. Therefore, we report on a patient with multilevel cervical disc herniations at C2-3, C3-4, and C4-5 who underwent anterior cervical discectomy with CDA for all three discs. To our knowledge, this is the first case report demonstrating a CDA at $\mathrm{C} 2-3$, which also involved three consecutive levels from $\mathrm{C} 2$ to $\mathrm{C} 5$.

\section{Illustrative Case}

A 52-year-old man presented with neck and right arm pain and right hand numbness that had persisted for years and was referred to our neurosurgical clinic for progression of myelopathic symptoms. He had tried medical treatment and physical therapy for more than 6 months before visits to the clinic. His symptoms, pain, and numbness persisted despite medical management, including physiotherapy, injections, and rehabilitation. The magnetic resonance images demonstrated multilevel cervical disc herniations at C2-3, C3-4, and $\mathrm{C} 4-5$, with marked compression of the dural sac and nerve roots (Fig. 1). The preoperative computed tomography scan ruled out OPLL over the cervical spine. Also, the lateral flexion and extension dynamic radiographs demonstrated successfully that the cervical spine was mobile from $\mathrm{C} 2$ to $\mathrm{C} 7$.

He then opted to undergo standard anterior cervical discectomies with CDA using Mobi-C (Zimmer-Biomet) artificial discs for C2-3, C3-4, and C4-5 levels (Figs. 2-4). During the operation, generous decompression of the neural structure was achieved with removal of bilateral uncovertebral joints and bone spurs using highspeed burrs or Kerrison's rongeurs under the microscope. After

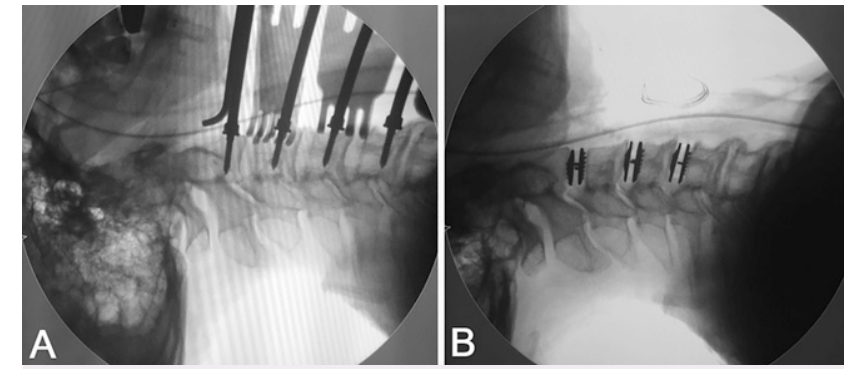

FIG. 2. Intraoperative fluoroscopy. A: Insertion of Caspar pins. B: After placement of all three artificial discs.

resection of the posterior longitudinal ligament, underlying dural matter with pulsatile movements was observed for confirmation of decompression at all three levels. Meticulous endplate preparation, selection of an appropriately fitted size of implant, and accurate centering of the device during insertion of the artificial discs were carried out to ensure the best function of the artificial discs. ${ }^{28} \mathrm{We}$ used copious saline irrigation persistently to wash away bone dust during spur drilling in the hopes of mitigating the chance of developing heterotopic ossification. The surgery, performed by the senior neurosurgeon and author of this report (J.C.W.), went smoothly without complications. The course of hospitalization was free of adverse events, and the neurological symptoms were promptly relieved after CDA. For this patient, there was no C5 palsy, no dysphagia, no hoarseness, and no dysphonia after the operation. The postoperative radiographs of flexion/extension lateral films at 24 months demonstrated preserved ROM at all levels (preoperatively $6.7^{\circ}, 8.8^{\circ}$, and $8.8^{\circ}$ versus postoperatively $6.0^{\circ}, 9.5^{\circ}$, and $8.4^{\circ}$ at C2-3, C3-4, and C4-5, respectively; Fig. 5).

\section{Discussion \\ Observations}

In this case report, we demonstrate that in a suitably selected patient, standard anterior cervical discectomies and arthroplasty can be successfully achieved at $\mathrm{C} 2-3$. Moreover, the three consecutive
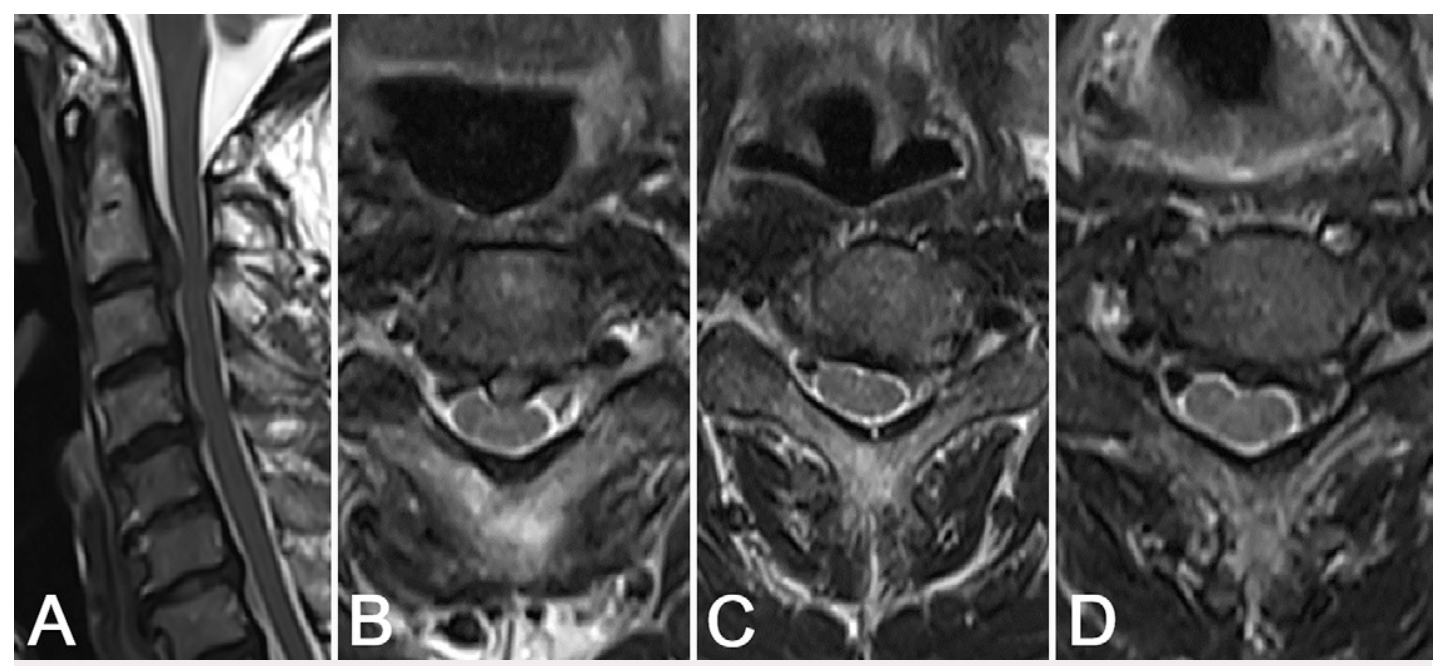

FIG. 1. Preoperative magnetic resonance images. A: Midsagittal view. B: C2-3 axial view. C: C3-4 axial view. D: C4-5 axial view. 


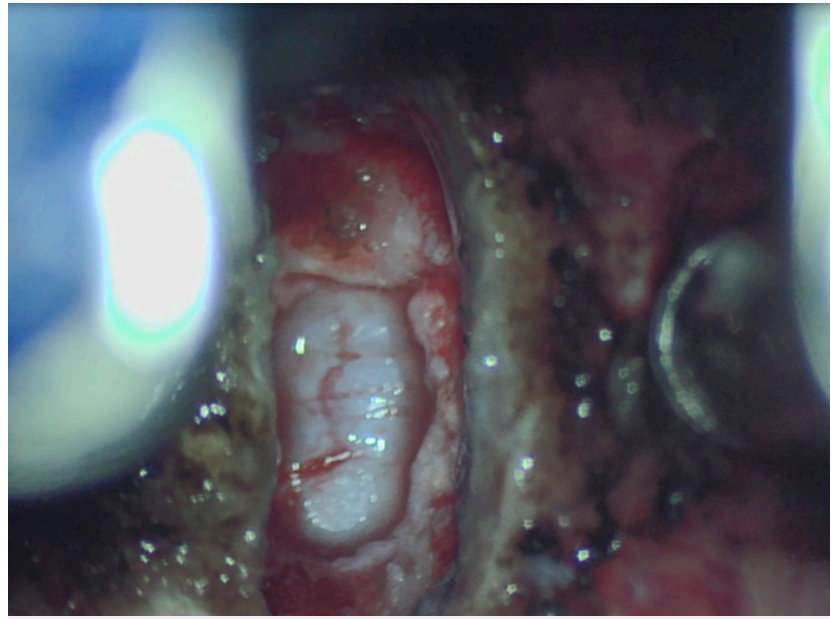

FIG. 3. Intraoperative photograph after C2-3 anterior discectomy.

levels of discectomy and artificial disc implantation from C2 to C5 yielded successful results in this patient. Postoperatively, the ROM at each level was well preserved at up to 24 months' follow-up. Although CDA at C2-3 has not been accepted as a standard treatment for cervical degeneration and disc herniation, it appeared to be a viable and safe option. Certainly, CDA is contraindicated for OPLL and traumatic cases such as hangman's fracture or fracture dislocation. For relatively young patients who have competent facets and fairly normal cervical lordosis but only disc herniations involving $\mathrm{C} 2-3$, the choice of preservation of segmental mobility using CDA is reasonable and deserves attention in the field of spinal surgery.

There are many surgical approaches to disc herniations at $\mathrm{C} 2-3$. Although various surgical approaches at $\mathrm{C} 2-3$ have been described, there is no consensus on the optimal choice. This is probably due to the low incidence of cervical disc herniation at $\mathrm{C} 2-3$, as low as $1 \%$ in some published series, and the anatomical difficulties that could preclude the common ACDF surgery. No large study was conducted and there is no consensus about the optimal management of cervical disc herniation at such a high level as C2-3. ${ }^{29}$ Retrospective studies and reviews have been supportive of the anterior approach for C2-3, ${ }^{8,29-31}$ and C2-3 ACDF has been a widely accepted procedure after discectomy. As an alternative, this case report illustrated that CDA can also be performed effectively and safely for C2-3 disc herniation, besides fusion.

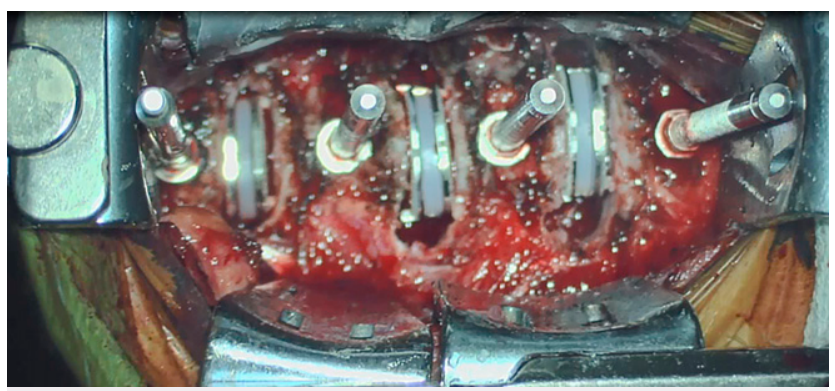

FIG. 4. Intraoperative photograph after placement of all three artificial discs.
This patient was a 52-year-old person who sustained a threelevel disc herniation and myeloradiculopathy from $\mathrm{C} 2$ to $\mathrm{C} 5$. There was no absolute contraindication for CDA, such as OPLL, spinal trauma, fracture, segmental instability, kyphotic deformity, infection, or long-term steroid use. There was no systemic disease such as malignancy, metabolic bone disease, autoimmune disease, spondyloathropathy (rheumatoid arthritis or ankylosing spondylitis), or cerebrovascular disease in this patient either.

Wu et al. suggested that less heterotopic ossification would be observed if soft disc herniation was the major cause in comparison to spondylosis. ${ }^{32}$ Preoperative images disclosed that there was little spondylosis in our case but more soft disc herniation at each level, which further proposed a favorable outcome after CDA. Preoperatively, lateral flexion/extension radiographs suggested that all segments remained mobile from $\mathrm{C} 2$ to $\mathrm{C} 7$, especially when the ROM was $6.7^{\circ}$ at $\mathrm{C} 2-3$. The posterior approach is a safe choice for high cervical lesions, but postoperative neck pain can be a concern. ${ }^{33} \mathrm{~A}$ hybrid construct involving C2-3 ACDF and C3-4 and C4-5 CDA may be a possible option if the anterior approach is considered. ${ }^{34-38}$ Our patient's will to maintain his neck mobility at all segments prompted us to aim for motion-preservation surgery at $\mathrm{C} 2-3$, and the results turned out to be satisfactory in the immediate postoperative period and at later follow-up.

Several anterior techniques are described for high cervical lesion, including the transoral approach, ${ }^{39}$ the anterolateral extradural approach, ${ }^{30,40}$ the submandibular approach, ${ }^{41}$ and the standard Cloward's anterior cervical approach. ${ }^{42}$ The transoral approach with or without mandible and tongue splitting allows comprehensive exposure at the craniocervical junction from the lower clivus to odontoid process. This approach also carries great morbidities and difficulty in postoperative oral feeding, so it should probably be preserved for ventral compressive lesions at the cervicomedullary junction. ${ }^{43}$ The anterolateral extradural approach allows clear exposure of the unilateral side of the upper cervical spine, but the risk involves vertebral artery dissection and injury to the spinal accessory nerve. It is technically demanding and requires experience for the lateral approach to the craniocervical junction. ${ }^{30}$ The submandibular approach avoids injury to the superior laryngeal nerve and hypoglossal nerve by dissecting a small corridor between the two nerves. It may be a nice choice for pure C2-3 lesions but is suboptimal for consecutive levels involving $\mathrm{C} 2-3$ and below. ${ }^{41}$ Cloward's technique is familiar to neurosurgeons and is probably the most reasonable approach in this case. Because this patient required three-level anterior discectomies from $\mathrm{C} 2$ to $\mathrm{C} 5$, the standard Cloward's technique provided excellent exposure to levels below the C3 vertebral body. Careful dissection starting from lower levels and gradually approaching $\mathrm{C} 2-3$ can prevent direct injury to the superior laryngeal nerve and hypoglossal nerve. Our patient's voice was not affected after this surgical procedure. Another major challenge can be obtaining a perpendicular angle to the $\mathrm{C} 2-3$ disc, which is a critical point for artificial disc placement. An oblique and superior projecting window will definitely jeopardize the placement and position of an artificial disc. In our experience, inserting a Caspar pin perpendicular to the $\mathrm{C} 2$ lower endplate offers great help in obtaining an optimal angle for artificial disc placement (Figs. 2 and 4).

The effectiveness and safety of two-level CDA have been examined in two FDA IDE trials investigating Prestige LP (Medtronic) and Mobi-C artificial discs. ${ }^{21,25}$ A hybrid construct combining twolevel CDA and one-level ACDF was reported to successfully treat 

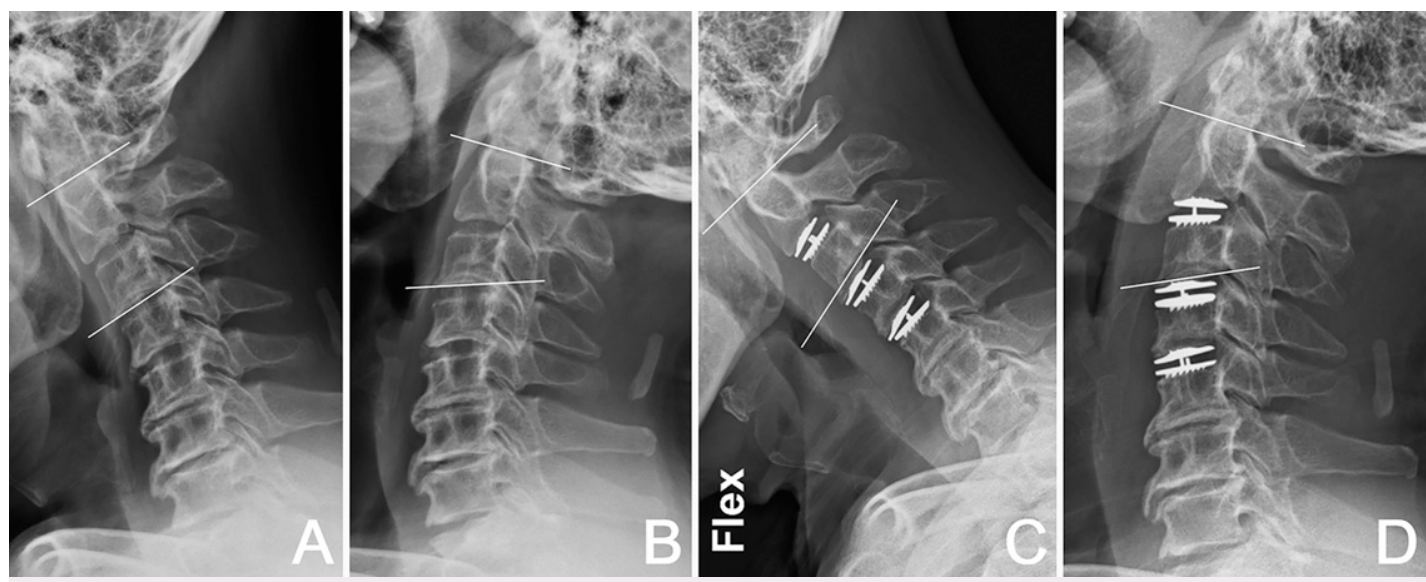

FIG. 5. A and B: Preoperative dynamic lateral radiographic film (flexion/extension). C and D: Postoperative dynamic lateral radiographic film (flexion/extension) at 24 months. Preoperatively $6.7^{\circ}, 8.8^{\circ}$, and $8.8^{\circ}$ versus postoperatively $6.0^{\circ}, 9.5^{\circ}$, and $8.4^{\circ}$ at C2-3, C3-4, and C4-5, respectively.

three-level spondylotic cervical myelopathy and disc herniation. ${ }^{44}$ Although there is no randomized control trial for three-level CDA versus ACDF yet, one retrospective study has demonstrated satisfactory clinical outcomes after three-level CDA compared to threelevel ACDF. ${ }^{13}$ Radiographic outcomes also have shown that segmental ROM after three-level CDA can be well maintained at approximately 2 years' follow-up. In our case, the segmental ROM remained mobile at each level at 24 months (postoperatively 6.0 $9.5^{\circ}$, and $8.4^{\circ}$ at $\mathrm{C} 2-3, \mathrm{C} 3-4$, and $\mathrm{C} 4-5$, respectively; Fig. 5).

\section{Lessons}

In summary, this report illustrates the case involving a patient who successfully received a consecutive three-level CDA involving the high cervical level of $\mathrm{C} 2-3$. There were no surgical complications, and his neurological symptoms were promptly relieved. Segmental ROM was well preserved at all operated levels.

\section{References}

1. Cloward RB. The anterior approach for removal of ruptured cervical disks. J Neurosurg. 1958;15(6):602-617.

2. Smith GW, Robinson RA. The treatment of certain cervical-spine disorders by anterior removal of the intervertebral disc and interbody fusion. J Bone Joint Surg Am. 1958;40-A(3):607-624.

3. Fraser JF, Härtl R. Anterior approaches to fusion of the cervical spine: a metaanalysis of fusion rates. J Neurosurg Spine. 2007;6(4):298-303.

4. Oliver JD, Goncalves S, Kerezoudis P, et al. Comparison of outcomes for anterior cervical discectomy and fusion with and without anterior plate fixation: a systematic review and meta-analysis. Spine (Phila Pa 1976). 2018;43(7):E413-E422.

5. Deshmukh VR, Rekate HL, Sonntag VK. High cervical disc herniation presenting with $\mathrm{C}-2$ radiculopathy. Case report and review of the literature. J Neurosurg. 2004;100(3 suppl Spine):303-306.

6. Park SH, Sung JK, Lee SH, Park J, Hwang JH, Hwang SK. High anterior cervical approach to the upper cervical spine. Surg Neurol. 2007;68(5):519-524.

7. Tuite GF, Papadopoulos SM, Sonntag VK. Caspar plate fixation for the treatment of complex hangman's fractures. Neurosurgery. 1992;30(5):761-765.
8. Finn MA, MacDonald JD. C2-C3 Anterior cervical fusion: technical report. Clin Spine Surg. 2016;29(10):E536-E541.

9. Wu JC, Chang HK, Huang WC, et al. Radiological and clinical outcomes of cervical disc arthroplasty for the elderly: a comparison with young patients. BMC Musculoskelet Disord. 2019;20(1):115.

10. Tu TH, Lee CY, Kuo CH, et al. Cervical disc arthroplasty for lessmobile discs. J Neurosurg Spine. 2019;31(3):310-316.

11. Tu TH, Kuo CH, Huang WC, Fay LY, Cheng H, Wu JC. Effects of smoking on cervical disc arthroplasty. J Neurosurg Spine. 2019;30(2):168-174.

12. Huang WC, Wu JC. Preservation versus elimination of segmental motion in anterior cervical spine surgery. Neurospine. 2019;16(3):576-578.

13. Chang HK, Huang WC, Tu TH, et al. Radiological and clinical outcomes of 3-level cervical disc arthroplasty. J Neurosurg Spine. 2019;32(2):174-181.

14. Chang CC, Huang WC, Wu JC, Mummaneni PV. The option of motion preservation in cervical spondylosis: cervical disc arthroplasty update. Neurospine. 2018;15(4):296-305.

15. Mummaneni PV, Burkus JK, Haid RW, Traynelis VC, Zdeblick TA. Clinical and radiographic analysis of cervical disc arthroplasty compared with allograft fusion: a randomized controlled clinical trial. $J$ Neurosurg Spine. 2007;6(3):198-209.

16. Heller JG, Sasso RC, Papadopoulos SM, et al. Comparison of BRYAN cervical disc arthroplasty with anterior cervical decompression and fusion: clinical and radiographic results of a randomized, controlled, clinical trial. Spine (Phila Pa 1976). 2009;34(2):101-107.

17. Murrey D, Janssen M, Delamarter R, et al. Results of the prospective, randomized, controlled multicenter Food and Drug Administration investigational device exemption study of the ProDisc-C total disc replacement versus anterior discectomy and fusion for the treatment of 1-level symptomatic cervical disc disease. Spine $\mathrm{J}$. 2009;9(4):275-286.

18. Davis RJ, Kim KD, Hisey MS, et al. Cervical total disc replacement with the Mobi-C cervical artificial disc compared with anterior discectomy and fusion for treatment of 2-level symptomatic degenerative disc disease: a prospective, randomized, controlled multicenter clinical trial: clinical article. J Neurosurg Spine. 2013;19(5):532-545.

19. Phillips FM, Lee JY, Geisler FH, et al. A prospective, randomized, controlled clinical investigation comparing PCM cervical disc arthroplasty with anterior cervical discectomy and fusion. 2-year results 
from the US FDA IDE clinical trial. Spine (Phila Pa 1976). 2013;38(15):E907-E918.

20. Hisey MS, Bae HW, Davis R, et al. Multi-center, prospective, randomized, controlled investigational device exemption clinical trial comparing Mobi-C Cervical Artificial Disc to anterior discectomy and fusion in the treatment of symptomatic degenerative disc disease in the cervical spine. Int J Spine Surg. 2014;8:7.

21. Davis RJ, Nunley PD, Kim KD, et al. Two-level total disc replacement with Mobi-C cervical artificial disc versus anterior discectomy and fusion: a prospective, randomized, controlled multicenter clinical trial with 4-year follow-up results. J Neurosurg Spine. 2015;22(1):15-25.

22. Gornet MF, Burkus JK, Shaffrey ME, Argires PJ, Nian H, Harrell FE Jr. Cervical disc arthroplasty with PRESTIGE LP disc versus anterior cervical discectomy and fusion: a prospective, multicenter investigational device exemption study. J Neurosurg Spine. 2015;23(5):558-573.

23. Janssen ME, Zigler JE, Spivak JM, Delamarter RB, Darden BV II, Kopjar B. ProDisc-C total disc replacement versus anterior cervical discectomy and fusion for single-level symptomatic cervical disc disease: seven-year follow-up of the prospective randomized U.S. Food and Drug Administration Investigational Device Exemption Study. J Bone Joint Surg Am. 2015;97(21):1738-1747.

24. Phillips FM, Geisler FH, Gilder KM, Reah C, Howell KM, McAfee PC. Long-term outcomes of the US FDA IDE prospective, randomized controlled clinical trial comparing PCM cervical disc arthroplasty with anterior cervical discectomy and fusion. Spine (Phila $\mathrm{Pa}$ 1976). 2015;40(10):674-683.

25. Gornet MF, Lanman TH, Burkus JK, et al. Cervical disc arthroplasty with the Prestige LP disc versus anterior cervical discectomy and fusion, at 2 levels: results of a prospective, multicenter randomized controlled clinical trial at 24 months. J Neurosurg Spine. 2017;26(6):653-667.

26. Keachie K, Shahlaie K, Muizelaar JP. Upper thoracic spine arthroplasty via the anterior approach. J Neurosurg Spine. 2010;13(2):240-245.

27. Kobayakawa A, Kato $F$, Ito $K$, et al. Evaluation of sagittal alignment and range of motion of the cervical spine using multi-detector-row computed tomography in asymptomatic subjects. Nagoya J Med Sci. 2018;80(4):583-589.

28. Tu TH, Wu JC, Huang WC, Wu CL, Ko CC, Cheng H. The effects of carpentry on heterotopic ossification and mobility in cervical arthroplasty: determination by computed tomography with a minimum 2-year follow-up: clinical article. J Neurosurg Spine. 2012;16(6):601-609.

29. Kotil K, Sengoz A. The management in the C2-C3 disc herniations: a clinical study. Turk Neurosurg. 2011;21(1):15-21.

30. Türe U, Güçlü B, Naderi S. Anterolateral extradural approach for C2-C3 disc herniation: technical case report. Neurosurg Rev. 2008;31(1):117-121.

31. Antich PA, Sanjuan AC, Girvent FM, Simó JD. High cervical disc herniation and Brown-Sequard syndrome. A case report and review of the literature. J Bone Joint Surg Br. 1999;81(3):462-463.

32. Wu JC, Huang WC, Tu TH, et al. Differences between soft-disc herniation and spondylosis in cervical arthroplasty: CT-documented heterotopic ossification with minimum 2 years of follow-up. J Neurosurg Spine. 2012;16(2):163-171.

33. Cheung JP, Luk KD. Complications of anterior and posterior cervical spine surgery. Asian Spine J. 2016;10(2):385-400.
34. Hey HW, Hong CC, Long AS, Hee HT. Is hybrid surgery of the cervical spine a good balance between fusion and arthroplasty? Pilot results from a single surgeon series. Eur Spine $J$. 2013;22(1):116-122.

35. Ding F, Jia Z, Wu Y, Li C, He Q, Ruan D. Fusion-nonfusion hybrid construct versus anterior cervical hybrid decompression and fusion: a comparative study for 3-level cervical degenerative disc diseases. Spine (Phila Pa 1976). 2014;39(23):1934-1942.

36. Jia Z, Mo Z, Ding F, He Q, Fan Y, Ruan D. Hybrid surgery for multilevel cervical degenerative disc diseases: a systematic review of biomechanical and clinical evidence. Eur Spine J. 2014;23(8):1619-1632.

37. Kan L, Kang J, Gao R, Chen X, Jia L. Clinical and radiological results of two hybrid reconstructive techniques in noncontiguous 3level cervical spondylosis. J Neurosurg Spine. 2014;21(6):944-950.

38. Grasso G. Clinical and radiological features of hybrid surgery in multilevel cervical degenerative disc disease. Eur Spine J. 2015;24(suppl 7):842-848.

39. Campbell SF, Tannenberg AE, Mowat P. Transoral resection of retro-odontoid disc sequestration: case report and review of the literature. J Clin Neurosci. 2000;7(4):325-327.

40. Song Y, Tharin S, Divi V, Prolo LM, Sirjani DB. Anterolateral approach to the upper cervical spine: case report and operative technique. Head Neck. 2015;37(9):E115-E119.

41. Russo A, Albanese E, Quiroga M, Ulm AJ. Submandibular approach to the C2-3 disc level: microsurgical anatomy with clinical application. J Neurosurg Spine. 2009;10(4):380-389.

42. Lu J, Ebraheim NA, Nadim Y, Huntoon M. Anterior approach to the cervical spine: surgical anatomy. Orthopedics. 2000;23(8):841-845.

43. Hadley MN, Spetzler RF, Sonntag VK. The transoral approach to the superior cervical spine. A review of 53 cases of extradural cervicomedullary compression. J Neurosurg. 1989;71(1):16-23.

44. Chang PY, Chang HK, Wu JC, et al. Is cervical disc arthroplasty good for congenital cervical stenosis? J Neurosurg Spine. 2017;26(5):577-585.

\section{Disclosures}

The authors report no conflict of interest concerning the materials or methods used in this study or the findings specified in this paper.

\section{Author Contributions}

Conception and design: all authors. Acquisition of data: all authors. Analysis and interpretation of data: all authors. Drafting the article: all authors. Critically revising the article: all authors. Reviewed submitted version of manuscript: all authors. Approved the final version of the manuscript on behalf of all authors: Chang. Administrative/technical/ material support: Chang, Wu. Study supervision: Chang, Wu.

\section{Correspondence}

Hsuan-Kan Chang: Neurological Institute, Taipei Veterans General Hospital, Taipei, Taiwan. hsuankanchang@gmail.com. 